\title{
PEMBELAJARAN METODE MULTISENSORI UNTUK MENINGKATKAN KEMAMPUAN PRA-MEMBACA PADA ANAK USIA PRA-SEKOLAH
}

\author{
Githa Mediana Br. Simanjuntak ${ }^{1}$, Rahma Widyana ${ }^{2}$, Kamsih Astuti ${ }^{3}$ \\ Universitas Mercu Buana Yogyakarta
}

\begin{abstract}
The research aimed to find out the effect of multisensory learning method to enhance pre-reading skill in pre-school age children. Data collection used measuring instrumen of pre-reading skill. Six pre-school age children were involved in this study. Data analyzing with using independent sample t-test show that $t$ value of 3,097 ( $p<0,05)$ and group mean difference of 17,667. It means that there is a significant difference between the group that treated by multisensory learning method and the group that treated by conventional learning method in school. In addition, data analyzing with using paired sample $t$-test show that $t$ value of $-3,991(p<0,05)$ and group mean difference of 12,167. It means that there is a significant enhancement before and after treated by multisensory learning method. In other words, there is an effect of multisensory learning method to enhance pre reading skill in pre school age children.
\end{abstract}

Keyword: Multisensory, pre-reading skill, pre-school age children

\begin{abstract}
Abstrak: Penelitian ini bertujuan untuk menemukan pengaruh metode pembelajaran multisensori dalam meningkatkan kemampuan pra membaca pada anak usia pra sekolah. Pengumpulan data menggunakan alat ukur kemampuan pra membaca. 6 anak usia prasekolah dilibatkan dalam penelitian ini. Analisis data dengan menggunakan independent sample t-test membuktikan bahwa menunjukkan nilai t sebesar 3,097 $(\mathrm{p}<0,05)$ dan perbedaan rata-rata kelompok sebesar 17,667. Hal tersebut berarti ada perbedaan kemampuan pra membaca yang signifikan antara kelompok yang diberi metode pembelajaran multisensori dengan metode pembelajaran konvensional di sekolah. Selain itu, analisis data dengan menggunakan paired sample t-test menunjukkan nilai t sebesar $3,991(\mathrm{p}<0,05)$ dan perbedaan rata-rata kelompok sebesar -12,167. Hal tersebut berarti ada peningkatan yang signifikan sebelum dan sesudah diberikan metode pembelajaran multisensori. Dengan kata lain, ada pengaruh pembelajaran menggunakan metode multisensori yang signifikan untuk meningkatkan kemampuan pra membaca pada anak usia pra sekolah.
\end{abstract}

Kata kunci: Multisensori, kemampuan pra membaca, anak usia pra sekolah

\footnotetext{
'Universitas Mercu Buana Yogyakarta, Email: githamediana回gmail.com

${ }^{2}$ Universitas Mercu Buana Yogyakarta, Email: rahma国mercubuana-yagya.ac.id

${ }^{3}$ Universitas Mercu Buana Yogyakarta, Email: kamsih@mercubuana-yagya.ac.id
} 


\section{PENDAHULUAN}

Kemampuan membaca menjadi hal yang penting bagi perkembangan akademik anak dan harus dimiliki oleh semua siswa. Melalui membaca, siswa dapat belajar banyak tentang berbagai bidang studi (Abdurrahman, 2009). Fenomena yang terjadi saat ini adalah syarat utama masuk sekolah dasar adalah kemampuan membaca yang baik. Syarat tersebut bertolak belakang dengan target pengajaran di tingkat sebelumnya, yaitu Taman Kanak-kanak dimana belum terdapat peraturan pendidikan nasional yang mengharuskan pendidikan usia preschool menggunakan pedagogi yang berkaitan dengan kemampuan membaca.

Salah satu tahap membaca permulaan adalah tahapan pra-membaca. Óllafsdottir (2016) menjelaskan bahwa anak usia pra-sekolah perlu dimotivasi untuk belajar dan merasakan bahwa membaca adalah hal yang harus diminati oleh mereka. Permasalahan yang terjadi adalah guru mengalami kesulitan karena keterbatasan kosakata bahasa dan pengenalan huruf yang dimiliki siswa, karena siswa lebih sering menggunakan bahasa daerah. Siswa sulit duduk diam untuk memegang buku dan sulit menebak kata yang memiliki kesamaan suku kata awal.

Penelitian Dewi (2015) membuktikan bahwa metode multisensori dapat meningkatkan kemampuan membaca permulaan dan pada anak kelas awal SD. Penelitian Sukaesi (2016) menemukan bahwa metode bermain kartu kata bergambar dapat meningkatkan kemampuan pra membaca pada anak TK. Selain itu, penelitian Fitriya (2014) membuktikan bahwa kemampuan pra membaca dapat ditingkatkan melalui media permainan kartu huruf. Berdasarkan penelitianpenelitian tersebut, belum ada penelitian mengenai kemampuan pra membaca anak usia pra sekolah dengan metode pembelajaran multisensori.
Berdasarkan uraian latar belakang masalah di atas, maka peneliti melihat bahwa dalam permasalahan yang terjadi, guru belum dapat menyajikan pembelajaran yang aktif, yakni guru mengajar dengan metode konvensional tanpa melibatkan sensori visual, auditori, dan kinestetik-taktil. Hal ini perlu ditindaklanjuti, mengingat metode belajar yang aktif dan merangsang semua alat indera lebih efektif bagi anak pra sekolah karena sesuai dengan kebutuhan dan karakteristik psikologis anak (Ruhaena, 2008). Oleh karena itu, tujuan dari penelitian ini adalah untuk melihat pengaruh metode pembelajaran multisensori dalam meningkatkan kemampuan pra membaca pada anak usia pra-sekolah.

\section{METODE PENELITIAN}

Penelitian ini metode eksperimen dengan pretest-posttest control group design sebagai desain penelitian. Sugiyono (2012) menjelaskan bahwa dalam desain penelitian tersebut, ada dua kelompok yang dipilih secara random, kemudian kelompok eksperimen dan kontrol diberi pretest untuk mengetahui kondisi awal antara kedua kelompok tersebut. Selanjutnya, setelah diberikan pretest, kelompok eksperimen diberikan perlakuan (X), sedangkan kelompok kontrol tidak diberi perlakuan (-), lalu keduanya diberikan posttest setelah perlakuan pada kelompok eksperimen. Dalam penelitian ini, kelompok eksperimen diberi pembelajaran multisensori menggunakan teknik Gillingham yang diadaptasi oleh Gearheart (1976), kelompok kontrol diberi pembelajaran konvensional biasa, serta alat pretest dan posttest merupakan alat ukur kemampuan pra membaca yang disusun oleh peneliti berdasarkan aspek kemampuan pra membaca menurut Óllafsdottir (2016) dengan koefisien reliabilitas KR-21 sebesar 0,629. 


\section{HASIL DAN PEMBAHASAN}

Gambar 1 merupakan grafik perubahan kelompok eksperimen dan kontrol dilihat dari skor rata-rata pretest dan posttest. Hipotesis pertama yang diuji adalah perbedaan kemampuan pra membaca pada kelompok eksperimen dan kelompok kontrol pada kelompok posttest saja, dengan menggunakan teknik independent sample t-test. Ratarata skor kelompok eksperimen sebesar 37,50 , sedangkan rata-rata skor kelompok kontrol sebesar 19,83. Uji beda menunjukkan nilai $\mathrm{t}$ sebesar 3,097 $(\mathrm{p}<$ $0,05)$, dengan perbedaan rata-rata kelompok sebesar 17,667, yang artinya ada perbedaan kemampuan pra membaca yang signifikan antara kelompok yang diberi metode pembelajaran multisensori dengan metode pembelajaran konvensional di sekolah.

Hipotesis kedua yang diuji adalah peningkatan kemampuan pra membaca sebelum dan sesudah diberi perlakuan (kelompok eksperimen). Hipotesis ini diuji dengan menggunakan teknik paired sample t-test. Rata-rata skor pada pretest kelompok eksperimen sebesar 25,33, sedangkan rata-rata skor pada posttest sebesar 37,50. Uji beda menunjukkan nilai $t$ sebesar $-3,991(p<0,05)$, dengan perbedaan rata-rata kelompok sebesar 12,167, yang artinya ada peningkatan yang signifikan sebelum dan sesudah diberikan metode pembelajaran multisensori.

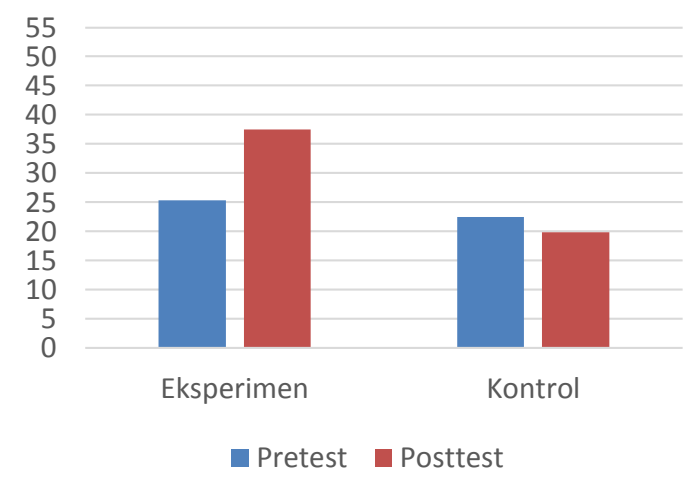

Gambar 1. Grafik Perubahan \begin{tabular}{rrr}
\multicolumn{2}{c}{ Pendekatan multisensori dalam } \\
pengajaran pra membaca ini
\end{tabular} memanfaatkan sensori visual (mata), auditori (telinga), dan kinestetik-taktil (gerakan tangan). Sensori visual (mata) yaitu dengan stimulus kartu huruf dan kartu gambar yang dilihat oleh anak, auditori (telinga) yaitu dengan suara bunyi huruf dan nyanyian yang diajarkan peneliti kepada anak, dan kinestetik-taktil (gerakan tangan) yaitu dengan gerakan tangan membentuk huruf di udara serta rabaan jari anak pada kayu huruf. Ketiga sensori ini dioptimalkan dalam proses pengenalan huruf secara simultan dan saling mendukung sehingga anak dapat menyimpan bentuk, kode dan nama huruf lebih mudah (Ruhaena, 2015). Dengan cara mengoptimalkan sensori anak ini, maka akan meningkatkan daya ingat dan proses belajar, yaitu ketika anak diajarkan untuk mengkaitkan bunyi huruf dengan simbol/bentuk tertulis dan meraba serta menuliskan bentuk hurufnya di udara.

Hasil penelitian ini juga didukung oleh hasil penelitian Marwiyati dan Hidayatulloh (2019) yang menyatakan bahwa berbagai kegiatan yang bervariasi yang menyenangkan akan membantu dalam menstimulasi perkembangan literasi. Hal ini dapat berfungsi optimal terutama bagi anak yang belum bisa membaca. Lebih lanjut, Marwiyati dan Hidayatulloh (2019) menjelaskan bahwa keberhasilan anak untuk dapat membaca didukung dengan adanya keselarasan antara keluarga, sekolah, dan masyarakat. Dengan keselarasan elemen-elemen sosial tersebut, mampu mencetak generasi yang cerdas, kreatif, dan berkarakter.

\section{KESIMPULAN}

Berdasarkan hasil uji statistik dan pembahasan dalam penelitian maka diperoleh kesimpulan bahwa ada pengaruh pembelajaran menggunakan metode multisensori yang signifikan untuk meningkatkan kemampuan pra 
membaca pada anak usia pra sekolah. Saran penelitian pada guru agar mengevaluasi kemampuan siswa agar jika ditemukan masalah maka akan segera bisa dilakukan untuk menentukan tindakan untuk mengatasi masalah tersebut dan melakukan inovasi terkait metode pembelajaran yang sesuai dengan usia pra sekolah juga. Pada orang tua untuk menerapkan metode pembelajaran multisensori di rumah. Pada peneliti selanjutnya, meneliti metode lain selain multisensori untuk meningkatkan pengenalan huruf, seperti menggunakan metode jolly phonics, fonemik, atau metode lainnya. Peneliti selanjutnya juga dapat meneliti variabel lain, seperti kemampuan pra membaca, kemampuan membaca, kemampuan berhitung, kemampuan menulis, atau variabel lainnya dengan tetap menerapkan metode multisensori sebagai intervensi.

\section{DAFTAR PUSTAKA}

Abdurrahman, M. (2009). Pendidikan Bagi Anak Berkesulitan Belajar. Jakarta: Rineka Cipta.

Dewi, S. U. (2015). Pengaruh metode multisensori dalam meningkatkan kemampuan membaca permulaan pada anak kelas awal sekolah dasar. MODELING: Jurnal Program Studi PGMI, 2(1), 1-13.

Fitriya, A. N. (2014). Peningkatan kemampuan pra-membaca kata pada anak kelompok B TK Puside Musi melalui media permainan kartu huruf. Jurnal Pendidikan Anak, 3(2), 484488.

Gearheart, B. R. (1976). Teaching the Learning Disabled. Colorado: University of Northern Colorado.

Marwiyati, S., \& Hidayatulloh, M. A. (2019). Peran "Cakruk Baca Bergerak" dalam pengembangan literasi anak usia dini. AWLADY: Jurnal Pendidikan Anak, 4(2), 61-77.

Óllafsdóttir, Í. J. (2016). How Young Children Learn to Read. Iceland: University of Iceland.

Ruhaena, L. (2008). Pengaruh metode pembelajaran jolly phonics terhadap

kemampuan baca-tulis permulaan Bahasa Indonesia dan Bahasa Inggris pada anak prasekolah. Jurnal Penelitian Humaniora, 9(2), 192-206.

Ruhaena, L. (2015). Model multisensori: solusi stimulasi literasi anak prasekolah. Jurnal Psikologi2, 42(1), 47-60.

Sugiyono, S. (2012). Metode Penelitian Kuantitatif, Kualitatif, dan $R \& D$. Jakarta: Alfabeta.

Sukaesi, Y., \& Halimah, L. (2016). Meningkatkan kemampuan pra membaca pada anak Taman KanakKanak. Cakrawala Dini, Jurnal Pendidikan Anak Usia Dini, 7(1). 